\title{
Impulsivity and response inhibition in alcohol dependence and problem gambling
}

\author{
Andrew J. Lawrence • Jason Luty • Nadine A. Bogdan • \\ Barbara J. Sahakian • Luke Clark
}

Received: 22 April 2009 / Accepted: 10 August 2009/Published online: 3 September 2009

(C) The Author(s) 2009. This article is published with open access at Springerlink.com

\begin{abstract}
Introduction Impulsivity is a central feature of drug addiction and may arise as a result of impaired inhibitory control. The extent to which inhibitory deficits arise as a consequence of drug exposure or relate to pre-existing addiction vulnerability is unknown.

Materials and methods This study compared measures of impulsivity in outpatients with alcohol dependence $(n=23)$ and problem gambling $(n=21)$, a putative behavioural
\end{abstract}

A. J. Lawrence $\cdot$ B. J. Sahakian · L. Clark

Behavioural and Clinical Neuroscience Institute (BCNI),

University of Cambridge,

Cambridge CB2 3EB, UK

A. J. Lawrence $\cdot$ L. Clark

Department of Experimental Psychology,

University of Cambridge,

Cambridge CB2 3EB, UK

J. Luty

Southend Community Drug and Alcohol Service,

South Essex Partnership NHS Trust,

Essex SS1 2NY, UK

N. A. Bogdan

Derwent Centre, North Essex Partnership Foundation Trust,

Harlow,

Essex CM20 1QX, UK

B. J. Sahakian

Department of Psychiatry, School of Clinical Medicine,

University of Cambridge,

Cambridge CB2 2QQ, UK

L. Clark $(\bowtie)$

Behavioural and Clinical Neuroscience Institute, Department of Experimental Psychology, University of Cambridge,

Downing St.,

Cambridge CB2 3EB, UK

e-mail: 1c260@cam.ac.uk addiction where direct effects of drug exposure may be minimal. Healthy controls $(n=27)$ were also tested, in a cross-sectional design. Subjects completed the stop-signal test as a neurocognitive probe of response inhibition, alongside self-report ratings of impulsivity, adult ADHD and OCD.

Results On the stop-signal test, Go reaction time and stopsignal reaction time were significantly slower in the alcohol-dependent group, compared with healthy controls. Healthy controls slowed their responding after successful and failed stop trials. Slowing after failed stop trials was significantly attenuated in the alcohol-dependent subjects. Go reaction time and post-error slowing were correlated with chronicity and severity, respectively, in the alcoholdependent subjects. Problem gamblers did not differ significantly from controls on the stop-signal test, despite trait elevations in impulsivity ratings.

Conclusion Inhibitory control is impaired in alcohol dependence but occurs in the context of psychomotor slowing. In addition, alcohol-dependent individuals failed to show behavioral adjustment following failed stops. These deficits may represent direct effects of chronic alcohol administration on fronto-striatal circuitry.

Keywords Compulsivity · Executive function .

Post-error adjustment $\cdot$ Pathological gambling $\cdot$ Alcoholism

\section{Introduction}

Impulsivity can be defined as a tendency towards unplanned actions, and is widely implicated in the development and maintenance of addictive behaviours (Verdejo-Garcia et al. 2008). As a personality trait, impulsivity is assessed using self-report questionnaires such as the Barratt Impulsivity Scale (BIS) (Patton et al. 
1995), and these measures detect elevated impulsivity in regular users of various substances including stimulants, opiates, alcohol and Ecstasy (Verdejo-Garcia et al. 2008). At a neuropsychological level, impulsivity is thought to arise from an impairment of inhibitory control. This is a core component of executive function that is implemented by a network of cortical and subcortical structures including the lateral prefrontal cortex (PFC) (Aron et al. 2004; Jentsch and Taylor 1999; Lyvers 2000). One widely used neuropsychological probe of inhibitory control is the stopsignal test (Logan 1994), which assesses the ability to override a prepotent "Go" response upon presentation of an infrequent stop signal (an auditory beep). The task is highly sensitive to inhibitory deficits, because the difficulty of stopping can be adjusted for each subject by manipulating the delay between the Go stimulus and the stop signal. This allows estimation of a stop-signal reaction time (SSRT), which indexes the efficiency of the stopping process. In addition, the task can be used to assess basic psychomotor speed and behavioral adjustment processes, such as the tendency to slow responding following an error (Rabbitt 1966).

The stop-signal test has been used in several studies of stimulant users, who displayed a selective deficit in inhibitory function (i.e. slower SSRTs) in the presence of intact psychomotor speed (go reaction time) (Fillmore and Rush 2002; Monterosso et al. 2005). Abstinent cocaine users were also reported to show attenuated slowing of reaction time following stop-signal trials ( $\mathrm{Li}$ et al. 2006), which may indicate a deficit in performance monitoring mediated by the anterior cingulate cortex (Kaufman et al. 2003; Kerns et al. 2004; Li et al. 2009). The findings of impaired SSRT converge with other reports of impulsivity in stimulant users using alternative paradigms (Clark et al. 2006; Kirby and Petry 2004; Leland and Paulus 2005; Quednow et al. 2007; Salo et al. 2002). Neuropsychological measures of inhibitory control have been less widely studied in alcohol dependence, and findings are less consistent with regard to both response inhibition (e.g. Go-No Go task; Bjork et al. 2004; Duka et al. 2003; Mitchell et al. 2005; Rose and Duka 2008) and delay discounting (the tendency to choose small immediate rewards over larger delayed rewards; Bjork et al. 2004; Dom et al. 2006; Kirby and Petry 2004; Mitchell et al. 2005). The first aim of the present study was to thoroughly characterise performance on the stop-signal test in a group of outpatients with alcohol dependence.

The observations of impulsivity in addicted groups may arise through two possible routes, which are not mutually exclusive. Impulsivity may occur as a consequence of prolonged substance consumption, or may predate the onset of the addiction, associated with the vulnerability to addictive disorders (Verdejo-Garcia et al. 2008). It is difficult to separate these pathways in studies in current users. The second aim of the present study was to compare impulsivity and inhibitory control in alcohol dependence against a second group of problem gamblers. Problem gambling is a putative behavioural addiction that is thought to share aetiological overlap with substance use disorders including alcohol dependence (Petry et al. 2005; Potenza 2006; Slutske et al. 2000). Any progressive deterioration associated with chronic drug consumption is assumed to be minimal in problem gamblers. We reasoned that a shared deficit across both the alcohol-dependent and problem gambler groups would implicate a vulnerability marker, whereas an impairment that was selective to alcohol dependence would implicate a substance-related deterioration.

In addition to the neuropsychological probe of response inhibition, we administered the BIS (Patton et al. 1995), and two clinical self-report measures of relevance to problem gambling. Adult attention-deficit/hyperactivity disorder (ADHD) is highly co-morbid with problem gambling (Breyer et al. 2009; Carlton and Manowitz 1992; Specker et al. 1995), and impulsivity is regarded as a central deficit in ADHD (Barkley 1997; Nigg 2001). Children and adults with ADHD are robustly impaired on the stop-signal test (Lijffijt et al. 2005). We assessed ADHD symptoms using the ADHD Self Report Scale (ASRS) (Kessler et al. 2005), which has not previously been used in research studies of problem gambling. In addition, we aimed to assess compulsive tendencies using the Padua Inventory (Washington State University Revision; Burns et al. 1996), a measure of sub-clinical obsessive-compulsive disorder (OCD) symptoms. Some researchers have conceptualised problem gambling and other DSM impulse control disorders as lying along an 'impulsive-compulsive' spectrum, with OCD identified as the prototypical compulsive condition (Grant and Potenza 2006; Hollander and Wong 1995; McElroy et al. 1994). Thus, an ancillary aim of the present study was to explore the presence of these comorbidities in a non-clinical group of problem gamblers recruited in the community and to compare the clinical ratings from this putative behavioural addiction against a known substance addiction (alcohol dependence).

\section{Methods}

\section{Participants}

Three groups of participants were recruited: outpatients with alcohol dependence ( $n=23)$, subjects with problem gambling or probable pathological gambling $(n=21)$ and healthy controls $(n=27)$. All subjects were male. Alcohol dependent individuals were recruited from treatment centres in Southend-on-Sea and Cambridge, UK, with DSM-IV diagnoses confirmed in a semi-structured interview with a 
psychiatrist (J.L., N.A.B.). The degree of dependency was assessed with the Severity of Alcohol Dependence Questionnaire (SADQ; Stockwell et al. 1979). Age of onset of problem drinking ranged from 11 to 35 years $(21.9 \pm 7.6)$ and duration of problem drinking, from 4.0 to 38.7 years (17.2 \pm 9.9$)$. Eleven patients in the alcohol-dependent group were taking medication (disulfiram, $n=3$; antidepressants, $n=7$; both, $n=1)$. Sobriety at time of testing was confirmed by breath alcohol readings $<0.01 \mathrm{mg} / \mathrm{L}$ (Lion Alcometer S-D2; Lion Laboratories Ltd., Barry, UK). Four subjects had consumed alcohol in the past $48 \mathrm{~h}$ (but were sober at testing), and all others were abstinent for $>1$ week, with 16 in remission.

Problem gamblers were recruited through community advertisement in Cambridge, UK and the GamCare website (www.gamcare.org.uk). All subjects scored $\geq 3$ on the South Oaks Gambling Screen (SOGS) (Lesieur and Blume 1987), indicative of 'problem gambling', and $16(76 \%)$ met the more stringent criteria for 'probable pathological gambling' (SOGS $\geq 5$ ). Healthy controls were recruited through community advertisement and from a panel of research volunteers. Controls and alcohol-dependent subjects scored $\leq 2$ on the SOGS. Exclusion criteria for all groups were: age over 65, co-morbid psychiatric illness, history of head injury, or neurological disorder, assessed by means of a locally developed screening questionnaire. The protocol was approved by the Cambridge Research Ethics Committee and all volunteers provided written informed consent.

Participants completed a number of self-report questionnaires to assess impulsivity and related clinical constructs: (1) Barratt Impulsivity Scale (version 11; Patton et al. 1995), a 30-item scale comprising three subscales (attentional, motor and non-planning) was used to assess trait impulsivity;(2) Padua OCD Inventory, Washington State University Revision (Burns et al. 1996), a 39-item scale with five subscales (contamination/washing, dressing/grooming, checking, thoughts of harm, impulses to harm), that indexes sub-clinical OCD behaviour; (3) ASRS Symptom Checklist (Kessler et al. 2005) to index symptoms of adult ADHD.

\section{Stop-signal test}

Subjects completed the stop-signal test as part of a neuropsychological assessment, with the other tasks reported separately (Lawrence et al. 2009). The stopsignal test took around $15 \mathrm{~min}$ to complete, on a $\mathrm{PC}$ computer using a two-button response box. On Go trials, the subject made a rapid two-choice button presses to leftor right- facing arrow stimuli (i.e. left arrow $=$ left button, right arrow $=$ right button). On a minority of trials $(25 \%)$, an auditory stop signal (a $300 \mathrm{~Hz}$ tone) followed the presentation of the arrow (stop trials). Subjects were instructed to attempt to inhibit their Go response on hearing the stop signal. The difficulty of stopping was varied by adjusting the delay between the onset of the Go signal and the stop signal, using a tracking staircase function with 50 ms steps: a failed stop trial reduced the subsequent delay by $50 \mathrm{~ms}$ and a successful stop increased the delay by $50 \mathrm{~ms}$. This method converges upon a stop-signal delay (SSD) at which the subject successfully stops on half the trials (the $\mathrm{SSD}_{50}$ ). The SSRT can be calculated by subtracting the $\mathrm{SSD}_{50}$ from the median go reaction time. The tracking procedure provides a superior estimation of the SSRT than blocked SSD procedures (Band et al. 2003).

Subjects completed five blocks of 64 trials, following a 16-trial practice of Go-only trials. Data from one problem gambler were lost due to software failure. Data were screened for outliers and to confirm convergence of the tracking function (Clark et al. 2005). Seven subjects (two controls, four alcohol-dependent, one problem gambler) failed to achieve convergence, either through too high $(>60 \%)$ or too low $(<40 \%)$ levels of successful inhibition. These staircase failures may arise through strategic slowing of the go reaction time, or through inconsistent performance or excessive distraction; they invalidate an assumption of the horserace model that Goand stop-related processes are independent (Logan 1994). As a consequence, these subjects were excluded from analyses. The final groups for analysis (with inhibition rates approximating 50\%) were 19 alcohol-dependent, 19 problem gamblers and 25 healthy controls.

Dependent variables were the SSRT, the median Go reaction time, and the total number of Go discrimination errors (e.g. a left button press to a right-facing arrow). In addition, post-error behaviour was analysed following Li et al. (2008): go reaction times were calculated for successful (non-error) Go trials in three conditions: (1) following Go trials $(\mathrm{pG}),(2)$ following successful stop trials (pSS), 3) following failed stop trials $(\mathrm{pFS})$. Given that the tracking algorithm aims to identify the $\mathrm{SSD}_{50}$, approximately equal numbers of pSS and pFS trials were expected. The rate of Go discrimination errors was too low to allow analysis of adjustment following Go errors.

Statistical analysis

Data were analysed with Statistical Package for the Social Sciences v15 (SPSS; Chicago, Illinois) using the principles set out in Cardinal and Aitken (2006) and Howell (2007). Behavioural data meeting assumptions of normality were analysed with analysis of variance (ANOVA), with twotailed tests thresholded at $p<.05$. Where ANOVA models contained a within-subjects variable with $>2$ levels, Mauchly's test of sphericity of the covariance matrix was applied. Where terms violated the sphericity assumption, degrees of freedom were corrected using GreenhouseGeisser's epsilon ( $\varepsilon$ is reported where this correction has 
been applied). Post-hoc investigation of effects of group was conducted using Fisher's LSD, as is appropriate for designs with three groups. Post-hoc differences in trial type used the SPSS 'simple' contrast with go reaction time as the control condition, adjusted for multiple comparisons using the Dunn-Sidak correction. Associations were tested using Kendall's Tau-b concordance coefficients to minimise the influence of outliers on the small sample sizes

\section{Results}

Demographic, clinical and personality data are reported in Table 1. There were no significant differences in age or years of education, although the ANOVA for age approached significance $(F(2,68)=2.68, p=0.076)$. The alcohol-dependent group were significantly older than the problem gamblers $(p=0.025)$, but importantly, neither target group differed significantly from the healthy controls.

On the BIS, there was a significant between-group difference on the total score and each of the subscales, and in each case, both the problem gamblers and alcoholdependent groups were significantly elevated compared with controls (see Table 1). On the BIS total, the problem gamblers also scored significantly higher than the alcoholdependent group $(p=.048)$. Whilst there was no significant difference on the Padua Inventory total score, there was a significant effect on the checking subscale $(F(2,68)=4.15$, $p=0.018$ ), with significantly higher scores in the alcoholdependent group compared with controls $(p=.007)$ and marginally higher scores in the problem gamblers compared with controls $(p=.060)$. On the ASRS, there was a significant group difference $(F(2,68)=4.54, p=0.014)$, with elevated scores in both the alcohol-dependent group $(p=0.017)$ and problem gamblers $(p=0.009)$ relative to controls, and no difference between the target groups $(p=0.780)$. A further analysis of the ASRS data applied a threshold of $\geq 14$ as indicative of a likely diagnosis of adult ADHD (Kessler et al. 2007). More subjects exceeded this threshold in the alcohol-dependent (30\%) and problem gambler $(38 \%)$ groups than in the healthy controls $(7 \%$; $\chi^{2}=7.28, d f=2, p=0.022$ ).

\section{Stop-signal task}

In the restricted sample used in the analysis of the stopsignal test, there was a fully significant group difference in age $(F(2,60)=4.19, p=0.020)$ but no difference in years of education $(F(2,60)=1.70, p=0.191)$. Age was correlated positively with both go reaction time $(T(63)=0.412$, $p<0.0001)$ and SSRT $(T(63)=0.245, p=0.005)$ in the overall sample, and was thus employed as a covariate in

Table 1 Demographic and self-report data in the alcohol-dependent (AD), problem gambler (PG) and healthy control (HC) groups. Values indicate mean $(\mathrm{SD})$

\begin{tabular}{|c|c|c|c|c|c|c|c|}
\hline & $\mathrm{AD}$ & PG & $\mathrm{HC}$ & Test statistic & $\mathrm{AD}$ vs. $\mathrm{HC}$ & PG vs. HC & $\mathrm{AD}$ vs. $\mathrm{PG}$ \\
\hline$n$ & 23 & 21 & 27 & & & & \\
\hline Age & $44.3(8.4)$ & $37.0(9.6)$ & $41.5(12.5)$ & $F(2,68)=2.68, p=0.076$ & ns & ns & $p=0.025$ \\
\hline Years of education & $12.3(3.2)$ & $12.9(2.9)$ & $14.0(2.7)$ & $F(2,68)=2.22, p=0.116$ & - & - & - \\
\hline SOGS & $0.6(0.8)$ & $9.7(5.8)$ & $0.3(0.5)$ & - & - & - & - \\
\hline SADQ & $31.4(16.8)$ & - & - & - & - & - & - \\
\hline \multicolumn{8}{|l|}{ Barratt Impulsivity Scale } \\
\hline Attention subscale & $19.0(3.8)$ & $20.3(3.0)$ & $16.6(4.2)$ & $F(2,68)=5.91, p=0.004$ & $p=0.032$ & $p=0.001$ & ns \\
\hline Motor subscale & $26.5(5.4)$ & $29.4(4.3)$ & $22.5(5.5)$ & $F(2,68)=11.0, p<0.0001$ & $p=0.007$ & $p<0.0001$ & ns \\
\hline Non-planning subscale & $25.9(4.4)$ & $27.5(3.1)$ & $21.3(5.2)$ & $F(2,68)=13.1, p<0.0001$ & $p<0.0001$ & $p<0.0001$ & ns \\
\hline Total & $71.3(10.7)$ & $77.1(6.9)$ & $60.4(10.2)$ & $F(2,68)=19.4, p<0.0001$ & $p<0.0001$ & $p<0.0001$ & $p=0.048$ \\
\hline \multicolumn{8}{|c|}{ Padua Inventory - Washington State University Revision } \\
\hline Contamination and washing & $3.5(2.7)$ & $3.6(3.7)$ & $4.9(6.6)$ & $F(2,68)=.638, p=0.532$ & - & - & - \\
\hline Dressing/grooming & $2.4(2.1)$ & $1.7(2.3)$ & $1.1(2.1)$ & $F(2,68)=2.21, p=0.118$ & - & - & - \\
\hline Checking & $10.1(8.3)$ & $8.8(4.5)$ & $5.6(4.1)$ & $F(2,68)=4.15, p=0.020$ & $p=0.007$ & $p=0.060$ & ns \\
\hline Thoughts of harm & $2.8(2.7)$ & $3.0(2.4)$ & $1.8(2.1)$ & $F(2,68)=1.65, p=0.199$ & - & - & - \\
\hline Impulses to harm & $1.7(2.2)$ & $1.4(1.6)$ & $1.1(1.8)$ & $F(2,68)=.754, p=0.475$ & - & - & - \\
\hline Total & $20.6(12.6)$ & $18.4(9.9)$ & $14.4(12.2)$ & $F(2,68)=1.81, p=0.172$ & - & - & - \\
\hline \multicolumn{8}{|l|}{ Adult ADHD Self-Report Scale } \\
\hline Total score & $12.0(4.4)$ & $12.3(3.1)$ & $9.3(4.0)$ & $F(2,68)=4.54, p=0.014$ & $p=0.017$ & $p=0.009$ & ns \\
\hline At-risk group & $7(30 \%)$ & $8(38 \%)$ & $2(7 \%)$ & $X^{2}=7.28, d f=2, p=0.022$ & - & - & - \\
\hline
\end{tabular}

SOGS South Oaks Gambling Screen, SADQ Severity of Alcohol Dependence Questionnaire, Ns non-significant 
the ANOVA models. ANOVA revealed a significant difference in go reaction time $(F(2,59)=8.08, p=0.001)$, due to slower responding in the alcohol-dependent group compared with controls $(p<0.0001)$ and problem gamblers ( $p=0.063$; see Table 2). Whilst the tracking function ensured that the probability of inhibition converged at approximately $50 \%$ in each group (alcohol-dependent $=48 \%$, problem gamblers $=47 \%$, healthy controls $=45 \%$ ), there was a small difference in $\mathrm{P}($ inhib) across groups $(F(2,59)=2.73$, $p=0.073$ ), and hence $\mathrm{P}($ inhib) was included as a covariate (along with age) in the ANOVA of SSRT. The effect of group on SSRT was significant $(F(2,58)=3.82, p=0.028)$, such that the alcohol-dependent group had significantly longer SSRTs than controls $(p=0.008)$. Within the alcoholdependent group, there were no differences in Go RT or SSRT as a function of medication status (both $t<0.725$, $p>0.10$ ). Could the deficit in go reaction time in the alcoholdependent group have arisen as strategic slowing in response to the stop signals? Three effects indicate that this is unlikely. First, analysis of reaction time data from the practice block (before introduction of the stop signal) confirmed psychomotor slowing in the alcohol-dependent group compared with controls $(p=.005)$. Second, in the alcohol-dependent group, there was no change in reaction time between the practice block and main task $(t(18)=0.128, p=0.899)$. Third, go reaction time and SSRT did not correlate within any group ( $\mathrm{Tau}=-0.07$ to $-0.17, p>0.23$ ).

In the analysis of post-signal slowing, ANOVA of the three trial types ( $\mathrm{pG}, \mathrm{pSS}$ and $\mathrm{pFS}$ ) revealed the expected significant effect of group $(F(2,59)=6.74, p=0.002)$ due to overall slowing in the alcohol-dependent group. The main effect of trial type was non-significant $(F(1.8,103.8)=0.398$, $p=0.646, \varepsilon=0.88)$ but there was a significant trial type by group interaction $(F(3.5,103.8)=2.59, p=0.048, \varepsilon=0.88)$. The interaction term (see Fig. 1) was driven by differences between the alcohol-dependent and healthy control groups (group $\mathrm{x}$ trial type: $F(2,82)=4.85, p=0.011)$. These groups differed in their responses following failed stops $(F(1,41)=$ $6.71, p=0.013)$ but not following successful stops $(F(1,41)=$

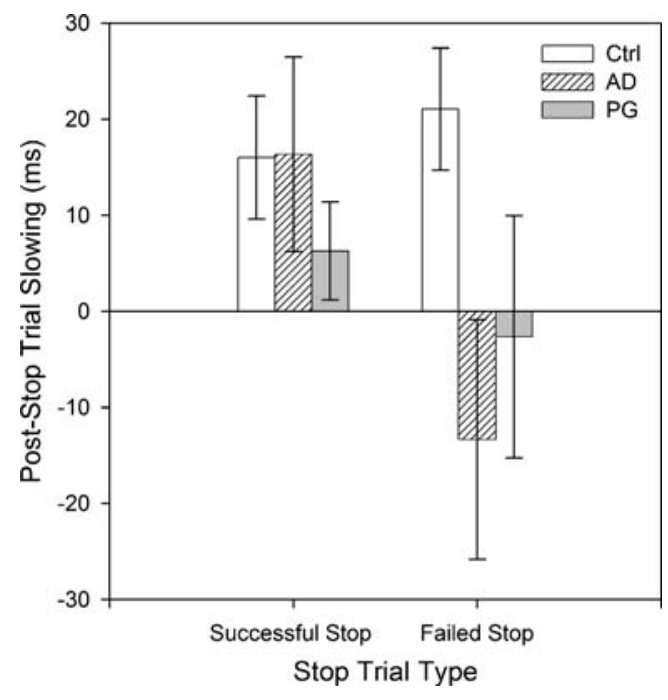

Fig. 1 The ordinate displays the difference in reaction time on successful and failed inhibitions, compared with a baseline of reaction time following a Go trial. There is a significant group by trial-type interaction due to abolished slowing after failed inhibitions in the alcohol-dependent $(A D)$ group, compared with the healthy controls $(H C)$. Problem gamblers $(P G)$ do not differ significantly from either group. Error Bars represent \pm 1 S.E.M

$0.004, p=0.951)$. Whilst controls showed significant slowing on pFS trials $(t(24)=3.31, p=0.004)$, the alcohol-dependent group showed a non-significant tendency to speed up on $\mathrm{pFS}$ trials (see Fig. $1 ; t(18)=1.07, p=0.3$ ). The group by trial-type interaction terms were not significant in the other paired ANOVAs of problem gamblers versus controls $(F(1.6,66.2)=$ $1.40, p=0.252, \varepsilon=0.81)$ or gamblers versus alcohol dependence $(F(1.6,57.0)=0.482, p=0.581, \varepsilon=0.82)$. Thus, performance in the problem gamblers fell between the control and alcohol-dependent groups and did not differ significantly from either.

In addition, we ran two sets of exploratory correlational analyses. Given the impairment on the stop-signal test in the alcohol-dependent group, we looked at the associations between stop-signal variables (SSRT, go reaction time, post-stop slowing) and clinical measures of alcohol depen-

Table 2 Performance on the stop-signal test in the alcohol-dependent (AD), problem gambler (PG) and healthy control (HC) groups, covarying for age. Values indicate mean (SD)

\begin{tabular}{llllllll}
\hline & AD & PG & HC & Test statistic & AD vs. HC & PG vs. HC & AD vs. PG \\
\hline$n$ & 19 & 19 & 25 & & & \\
Go reaction time (ms) & $485 \pm 88$ & $412 \pm 65$ & $394 \pm 57$ & $F(2,59)=8.08, p=0.001$ & $p<0.001$ & ns & $p=0.063$ \\
SSRT $^{\text {a }}(\mathrm{ms})$ & $212 \pm 51$ & $185 \pm 36$ & $184 \pm 46$ & $F(2,58)=3.82, p=0.028$ & $p=0.008$ & $\mathrm{~ns}$ & $\mathrm{~ns}$ \\
Go Errors $(N)$ & $2.6 \pm 3.4$ & $3.2 \pm 2.6$ & $2.9 \pm 2.5$ & $F(2,59)=0.01, p=0.992$ & - & - & $\mathrm{ns}$ \\
P(Inhib) (\%) & $48.2 \pm 4.8$ & $46.6 \pm 3.3$ & $45.2 \pm 3.6$ & $F(2,59)=2.73, p=0.073$ & $p=0.040$ & $\mathrm{~ns}$ \\
Practice RT (ms) & $483 \pm 73$ & $449 \pm 101$ & $403 \pm 61$ & $F(2,59)=6.34, p=0.003$ & $p=0.005$ & $p=0.004$ & $\mathrm{~ns}$ \\
\hline
\end{tabular}

NS non-significant, SSRT stop-signal reaction time, $P$ (inhib) probability of successful inhibition on stop trials

${ }^{\text {a }}$ Covarying for differences in $\mathrm{P}($ inhib), with test statistics based on estimated marginal means 
dence (SADQ score, age of onset, duration, length of abstinence) in the alcohol-dependent group. There was a positive association between go reaction time and duration of alcohol abuse $(T(19)=0.40, p=0.016)$, such that greater chronicity was associated with slower psychomotor function (see Fig. 2a). This association was not obviously explained by age (that more chronic cases tended to be older) or protracted withdrawal symptoms, as go reaction time was not significantly related to these variables (age $T(19)=0.235$, $p=.161$; days abstinent $T(19)=-047, p=0.779)$. There was a negative association between slowing following a failed inhibition and the SADQ score $(T(19)=-0.38, p=0.023)$, such that more severe dependence was associated with a speeding (rather than a slowing) of response speed following failed stop trials (see Fig. 2b). Second, we looked for associations between the self-report measures of impulsivity (BIS total, ASRS) and the three performance indices on the stop-signal test, in the collapsed sample $(n=63)$. Whilst the two self-report measures were related $(T=0.370, p<0.0001)$, no associations with stopping performance were significant $($ Tau $=-0.06$ to $-0.10, p>0.27)$.

\section{Discussion}

Individuals with alcohol dependence and problem gambling were compared on the stop-signal test, and additionally completed self-report measures of impulsivity. The questionnaire data indicated significant elevations in trait impulsivity (BIS) and adult ADHD symptoms (ASRS) in both target groups compared with healthy controls, consistent with the central role of impulsivity in current theoretical models of addiction (Goldstein and Volkow 2002; Jentsch and Taylor 1999). In contrast, the neurocognitive measure of response inhibition only detected a significant deficit in the alcohol-dependent group, who were impaired on multiple components of the task. The alcohol-dependent group displayed slower SSRTs, in the context of overall psychomotor slowing (go reaction time) in both the practice phase and the main task, and changes in post-signal adjustment. These variables did not indicate any significant differences between problem gamblers and healthy controls.

SSRT is considered the primary index of response inhibition on this task. Our finding of slower SSRTs in alcohol dependence extends previous reports in other forms of substance addiction including amphetamine (Monterosso et al. 2005) and cocaine (Fillmore and Rush 2002; Li et al. 2006) abuse. However, in these studies of current or abstinent substance users, it is not possible to separate whether a neurocognitive effect pre-dates the addiction, or arises as a consequence of prolonged substance use. In our study, SSRT did not differ in problem gamblers and healthy controls (mean $=185 \mathrm{~ms}$ and $184 \mathrm{~ms}$, respectively, compared with $212 \mathrm{~ms}$ in the alcohol-dependent group). Problem gambling is argued to represent a behavioural addiction that shares underlying vulnerability mechanisms with substance addiction (e.g. Potenza 2006), but without the damaging effects of drug use on brain structure and/or function. By this reasoning, the intact stop-signal performance in the problem gamblers may indicate that the deficit in alcohol dependence arises as a consequence of long-term alcohol consumption. Functional neuroimaging studies of the stop-signal test implicate a distributed cortical and subcortical network supporting efficient response inhibition, with a key foci in the lateral prefrontal cortex (PFC; more specifically, the right inferior frontal gyrus; Aron et al. 2003; Chambers et al. 2006). This is a likely substrate for the progressive effect in alcohol dependence; functional imaging studies have shown impaired recruitment of lateral prefrontal cortex during tasks of executive control in alcohol dependence (Dao-Castellana et al. 1998; Pfefferbaum et al. 2001; Schecklmann et al. 2007), neuropsychological studies show acute effects of alcohol and binge drinking upon executive functions associated with this region (Weissenborn and Duka 2003),
Fig. 2 Clinical predictors of task performance. a Slowed go reaction time (Go $R T)$ in the alcohol-dependent group was associated with greater duration of alcohol use (left). b Diminished post-error slowing (i.e. slowing after failures to stop on a stop-signal trial) in the alcohol-dependent group was associated with greater score on the Severity of Alcohol Dependence Questionnaire $(S A D Q)$
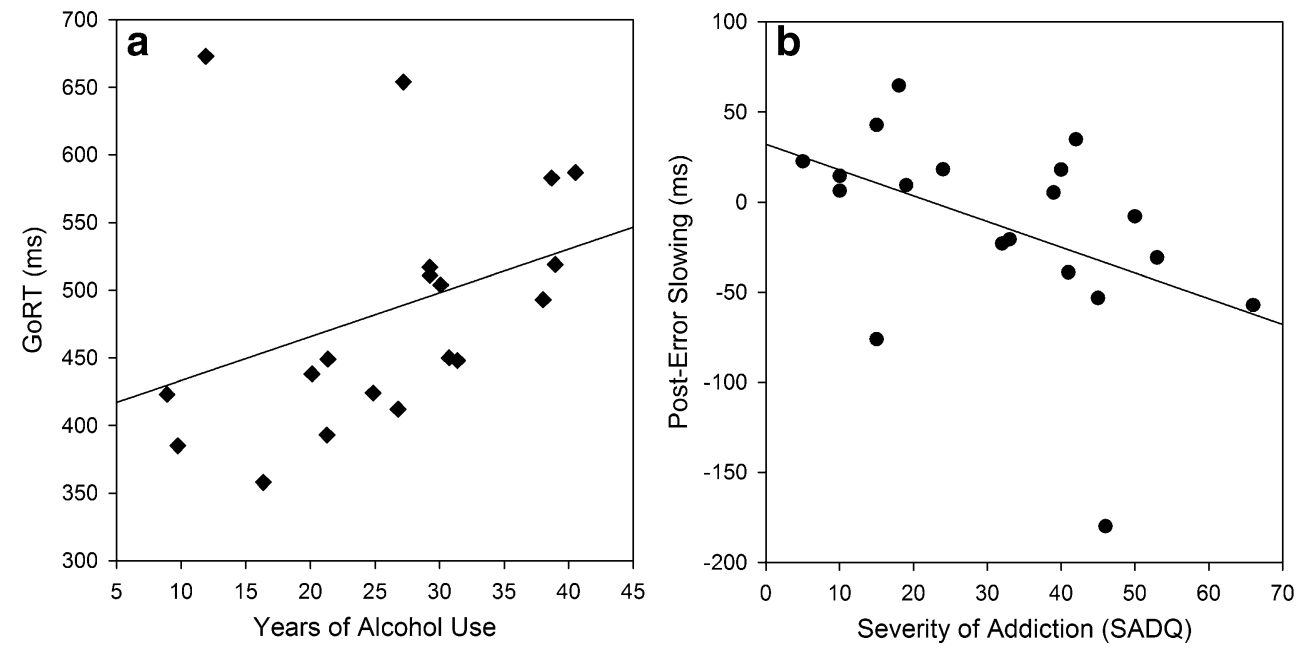
and structural imaging studies indicate frontal lobe shrinkage as a function of increased alcohol use (Kubota et al. 2001). By inference, the deficits in response inhibition observed in previous studies of stimulant and Ecstasy users (e.g. Clark et al. 2006; Fillmore and Rush 2002; Quednow et al. 2007) may also arise as a progressive consequence of drug exposure on frontal lobe function.

Reduced dorsolateral PFC activity was reported in a recent functional imaging study of the stop-signal test in alcohol-dependent individuals, in the key contrast of successful inhibitions minus inhibition failures ( $\mathrm{Li}$ et al. 2009). The behavioural data in that study did not reveal any difference in SSRT between the alcohol-dependent group (mean=190 ms) and healthy controls (mean=195 ms), but it should be noted that subjects were practiced extensively on the task (for $40 \mathrm{~min}$ ) prior to scanning, and this is likely to have severely blunted the behavioural sensitivity of the test. Our own findings are consistent with three recent neuropsychological studies that used the stop-signal test in alcohol dependence; Goudriaan et al. (2006) reported slower SSRTs compared with controls, but did not report other performance measures on the task. Glass et al. (2009) reported associations between both SSRT and go reaction time and measures of alcoholism severity in a large mixed sample of alcohol-dependent and non-alcohol-dependent men $(n=240)$. Wojnar et al. (2009) reported SSRTs close to our own in alcohol-dependent patients with (mean=230 ms) and without (mean $=216 \mathrm{~ms}$ ) a history of suicide attempt, but did not include a healthy control group for comparison, and also did not report other performance measures from the test.

The previous studies of stop-signal performance in stimulant users reported single dissociations between impaired SSRT and intact performance on basic Go responding (Fillmore and Rush 2002; Li et al. 2006; Monterosso et al. 2005). In our data, the alcohol-dependent group was additionally slowed in go reaction time. This is unlikely to represent a strategic decision to delay the response (i.e. in order to increase the likelihood of stop-signal detection), as the response latency was already slowed during a practice block prior to introduction of the stop signals, and did not change significantly between the practice and main task. Longer go reaction times were also seen in the functional imaging study of the stop-signal task in alcohol dependence (Li et al. 2009), and general psychomotor slowing is a common finding in alcohol-dependent samples (De Wilde et al. 2007). In our study, the slowing in go reaction time was associated with duration of alcohol abuse, which further supports the argument of a progressive effect of long-term alcohol use.

In addition, the alcohol-dependent group demonstrated impaired behavioural adjustment following failed inhibitions on the task. The healthy controls slowed their Go responding on trials following failed stops, compared with Go trials that followed other Go trials. This slowing of responses after an error is an adaptive process that has been associated with performance-monitoring and error-detection in medial prefrontal cortex (Kerns et al. 2004). This adjustment was abolished in the alcohol-dependent group, who were (non-significantly) faster following failed stops. Moreover, this change in response latency was related to an index of clinical severity, the SADQ score. Deficient post-error slowing on the stop-signal procedure has been reported in abstinent cocaine users ( $\mathrm{Li}$ et al. 2006) and may be related to hypofunction in medial or dorsolateral PFC during error detection (Kaufman et al. 2003; Li et al. 2009). Acute dosing of alcohol also disrupted error-related brain activity in healthy volunteers (Ridderinkhof et al. 2002). Thus, our findings corroborate other recent indications of abnormal behavioural adjustment processes in addiction.

The stop-signal test was used in two previous studies of problem gamblers. In the study by Rodriguez-Jimenez et al. (2006), there was no observable difference in SSRT between pathological gamblers and controls, but the authors report that those gamblers with ADHD features were significantly impaired in comparison to gamblers without ADHD features (neither group differed significantly from controls). However, Goudriaan et al. (2006) did report a significant difference in SSRT between treatment-seeking pathological gamblers and controls, which was also seen in two further groups with alcohol dependence and Tourette syndrome. Unfortunately, they did not report other task variables besides SSRT. The literature on broader aspects of executive function in problem gambling is also inconsistent (Cavedini et al. 2002; Forbush et al. 2008; Kalechstein et al. 2007; Leiserson and Pihl 2007), and it is conceivable that lateral PFC pathophysiology may give rise to a dysexecutive-type syndrome in only a subset of the most severe pathological gamblers (for example, the antisocial impulsive gamblers described by Blaszczynski and Nower (2002)). Whilst our gamblers were a community-recruited sample rather than a clinical group (due to the lack of available treatment facilities in the UK), the mean SOGS score of 9.8 is within the range of previous research (mean SOGS 9-13). Our group were also impaired on two tests of risky decision-making, described separately (Lawrence et al. 2009), and thus, it is unlikely that we simply recruited an anomalous high-functioning sample. It is also notable that we confirmed an elevation in trait impulsivity in our group, consistent with many previous studies (Verdejo-Garcia et al. 2008 for review). In this respect, our finding of elevated trait impulsivity in problem gamblers coupled with no significant difference on the stop-signal test echoes a recent paper by Forbush et al. (2008), who found that personality measures including impulsivity added significant incremental variance over a neuropsychological assessment in discriminating pathological gamblers and controls, but that neuropsychological variables did not add significantly over 
personality measures. Measures of trait impulsivity have also been shown to predict treatment retention in problem gamblers (Leblond et al. 2003) and to mediate depressive symptoms in regular gamblers (Clarke 2006).

As a final point, our measure of compulsivity detected only modest differences across the three groups, in contrast to the clear effects on trait impulsivity. There was no overall difference in the Padua Inventory total score, and a significant effect on the checking subscale was driven predominantly by the alcohol-dependent group, with a nonsignificant trend increase in the problem gamblers. Problem gambling has been conceptualised by some as aligned with OCD on an 'impulsive-compulsive spectrum' (Grant and Potenza 2006; Hollander and Wong 1995; McElroy et al. 1994), and some psychometric studies have reported increased compulsivity ratings in problem gamblers (Blaszczynski 1999; Frost et al. 2001). However, other data have failed to find significant co-morbidity between the two disorders (Kessler et al. 1994; Potenza 2006). We would support the recent conclusion by Blanco et al. (2009) that whilst both impulsive and compulsive features may be detectable in problem gamblers, the impulsive features predominate and are more closely associated with gambling severity.

In conclusion, this study has characterised performance on a neurocognitive probe of response inhibition, the stopsignal test, in alcohol dependence and problem gambling. The alcohol-dependent group were impaired on multiple aspects of the task, including the core index of response inhibition (SSRT) but also measures of psychomotor speed and behavioural adjustment. The observed changes in SSRT and behavioural adjustment (post-signal slowing) extend previous reports in stimulant users, indicating crosssubstance impairments in cognitive control in addiction. However, the absence of these impairments in a group with problem gambling, a putative behavioural addiction, implies that the observed changes in alcohol dependence (and other substance addictions) may arise as a detrimental effect of chronic substance intake on frontal lobe function.

Acknowledgments Supported by a project grant from the Economic and Social Research Council and Responsibility in Gambling Trust (RES-164-25-0010, LC and TW Robbins), a Wellcome Trust Programme Grant (TW Robbins, BJ Everitt, AC Roberts and BJS), and completed within the University of Cambridge Behavioural and Clinical Neuroscience Institute, supported by a consortium award from the Medical Research Council (UK) and the Wellcome Trust. AJL was supported by an MRC post-graduate studentship. The authors wish to thank Antonio Verdejo-Garcia, Alexis Jones and William Spencer for their assistance with recruitment.

Financial Disclosures L.C. and B.J.S. consult for Cambridge Cognition plc (http://www.camcog.com) which distributes the stopsignal task as a part of the CANTAB assessment battery. A.J.L., J.L., N.A.B. have no conflicts of interest to report.
Open Access This article is distributed under the terms of the Creative Commons Attribution Noncommercial License which permits any noncommercial use, distribution, and reproduction in any medium, provided the original author(s) and source are credited.

\section{References}

Aron AR, Fletcher PC, Bullmore ET, Sahakian BJ, Robbins TW (2003) Stop-signal inhibition disrupted by damage to right inferior frontal gyrus in humans. Nat Neurosci 6:115-116

Aron AR, Robbins TW, Poldrack RA (2004) Inhibition and the right inferior frontal cortex. Trends Cogn Sci 8:170-177

Band GP, van der Molen MW, Logan GD (2003) Horse-race model simulations of the stop-signal procedure. Acta Psychol (Amst) 112:105-142

Barkley RA (1997) Behavioral inhibition, sustained attention, and executive functions: constructing a unifying theory of ADHD. Psychol Bull 121:65-94

Bjork JM, Hommer DW, Grant SJ, Danube C (2004) Impulsivity in abstinent alcohol-dependent patients: relation to control subjects and type 1-/type 2-like traits. Alcohol 34:133-150

Blanco C, Potenza MN, Kim SW, Ibanez A, Zaninelli R, Saiz-Ruiz J, Grant JE (2009) A pilot study of impulsivity and compulsivity in pathological gambling. Psychiatry Res 167:161-168

Blaszczynski A (1999) Pathological gambling and obsessivecompulsive spectrum disorders. Psychol Rep 84:107-113

Blaszczynski A, Nower L (2002) A pathways model of problem and pathological gambling. Addiction 97:487-499

Breyer JL, Botzet AM, Winters KC, Stinchfield RD, August G, Realmuto G (2009) Young Adult Gambling Behaviors and their Relationship with the Persistence of ADHD. J Gambl Stud 25:227-238

Burns GL, Keortge SG, Formea GM, Sternberger LG (1996) Revision of the Padua Inventory of obsessive compulsive disorder symptoms: distinctions between worry, obsessions, and compulsions. Behav Res Ther 34:163-173

Cardinal RN, Aitken MRF (2006) ANOVA for the behavioural sciences researcher. Lawrence Erlbaum Associates, Mahwah, $\mathrm{NJ}$

Carlton PL, Manowitz P (1992) Behavioral restraint and symptoms of attention deficit disorder in alcoholics and pathological gamblers. Neuropsychobiology 25:44-48

Cavedini P, Riboldi G, Keller R, D'Annucci A, Bellodi L (2002) Frontal lobe dysfunction in pathological gambling patients. Biol Psychiatry 51:334-341

Chambers CD, Bellgrove MA, Stokes MG, Henderson TR, Garavan H, Robertson IH, Morris AP, Mattingley JB (2006) Executive "brake failure" following deactivation of human frontal lobe. J Cogn Neurosci 18:444-455

Clark L, Roiser JP, Cools R, Rubinsztein DC, Sahakian BJ, Robbins TW (2005) Stop signal response inhibition is not modulated by tryptophan depletion or the serotonin transporter polymorphism in healthy volunteers: implications for the 5-HT theory of impulsivity. Psychopharmacology (Berl) 182:570-578

Clark L, Robbins TW, Ersche KD, Sahakian BJ (2006) Reflection impulsivity in current and former substance users. Biol Psychiatry 60:515-522

Clarke D (2006) Impulsivity as a mediator in the relationship between depression and problem gambling Pers. Ind Diff 40:5-15

Dao-Castellana MH, Samson Y, Legault F, Martinot JL, Aubin HJ, Crouzel C, Feldman L, Barrucand D, Rancurel G, Feline A, Syrota A (1998) Frontal dysfunction in neurologically normal chronic alcoholic subjects: metabolic and neuropsychological findings. Psychol Med 28:1039-1048 
De Wilde B, Dom G, Hulstijn W, Sabbe B (2007) Motor functioning and alcohol dependence. Alcohol Clin Exp Res $31: 1820-1825$

Dom G, De Wilde B, Hulstijn W, van den Brink W, Sabbe B (2006) Decision-making deficits in alcohol-dependent patients with and without comorbid personality disorder. Alcohol Clin Exp Res 30:1670-1677

Duka T, Townshend JM, Collier K, Stephens DN (2003) Impairment in cognitive functions after multiple detoxifications in alcoholic inpatients. Alcohol Clin Exp Res 27:1563-1572

Fillmore MT, Rush CR (2002) Impaired inhibitory control of behavior in chronic cocaine users. Drug Alcohol Depend 66:265-273

Forbush KT, Shaw M, Graeber MA, Hovick L, Meyer VJ, Moser DJ, Bayless J, Watson D, Black DW (2008) Neuropsychological characteristics and personality traits in pathological gambling. CNS Spectr 13:306-315

Frost RO, Meagher BM, Riskind JH (2001) Obsessive-compulsive features in pathological lottery and scratch-ticket gamblers. J Gambl Stud 17:5-19

Glass JM, Buu A, Adams KM, Nigg JT, Puttler LI, Jester JM, Zucker RA (2009) Effects of alcoholism severity and smoking on executive neurocognitive function. Addiction 104:38-48

Goldstein RZ, Volkow ND (2002) Drug addiction and its underlying neurobiological basis: neuroimaging evidence for the involvement of the frontal cortex. Am J Psychiatry 159:1642-1652

Goudriaan AE, Oosterlaan J, de Beurs E, van den Brink W (2006) Neurocognitive functions in pathological gambling: a comparison with alcohol dependence, Tourette syndrome and normal controls. Addiction 101:534-547

Grant JE, Potenza MN (2006) Compulsive aspects of impulse-control disorders. Psychiatr Clin North Am 29:539-551

Hollander E, Wong CM (1995) Obsessive-compulsive spectrum disorders. J Clin Psychiatry 56(Suppl 4):3-6, discussion 53-55

Howell DC (2007) Statistical methods for psychology, 6th edn. Thomson Wadsworth, Belmont, CA

Jentsch JD, Taylor JR (1999) Impulsivity resulting from frontostriatal dysfunction in drug abuse: implications for the control of behavior by reward-related stimuli. Psychopharmacology (Berl) 146:373-390

Kalechstein AD, Fong T, Rosenthal RJ, Davis A, Vanyo H, Newton TF (2007) Pathological gamblers demonstrate frontal lobe impairment consistent with that of methamphetamine-dependent individuals. J Neuropsychiatry Clin Neurosci 19:298-303

Kaufman JN, Ross TJ, Stein EA, Garavan H (2003) Cingulate hypoactivity in cocaine users during a GO-NOGO task as revealed by event-related functional magnetic resonance imaging. J Neurosci 23:7839-7843

Kerns JG, Cohen JD, MacDonald AW 3rd, Cho RY, Stenger VA, Carter CS (2004) Anterior cingulate conflict monitoring and adjustments in control. Science 303:1023-1026

Kessler RC, McGonagle KA, Zhao S, Nelson CB, Hughes M, Eshleman S, Wittchen HU, Kendler KS (1994) Lifetime and 12-month prevalence of DSM-III-R psychiatric disorders in the United States. Results from the National Comorbidity Survey. Arch Gen Psychiatry 51:8-19

Kessler RC, Adler L, Ames M, Demler O, Faraone S, Hiripi E, Howes MJ, Jin R, Secnik K, Spencer T, Ustun TB, Walters EE (2005) The World Health Organization Adult ADHD Self-Report Scale (ASRS): a short screening scale for use in the general population. Psychol Med 35:245-256

Kessler RC, Adler LA, Gruber MJ, Sarawate CA, Spencer T, Van Brunt DL (2007) Validity of the World Health Organization Adult ADHD Self-Report Scale (ASRS) Screener in a representative sample of health plan members. Int J Methods Psychiatr Res 16:52-65

Kirby KN, Petry NM (2004) Heroin and cocaine abusers have higher discount rates for delayed rewards than alcoholics or non-drugusing controls. Addiction 99:461-471
Kubota M, Nakazaki S, Hirai S, Saeki N, Yamaura A, Kusaka T (2001) Alcohol consumption and frontal lobe shrinkage: study of 1432 nonalcoholic subjects. J Neurol Neurosurg Psychiatry 71:104-106

Lawrence AJ, Luty J, Bogdan NA, Sahakian BJ, Clark L (2009) Problem gamblers share deficits in impulsive decision-making with alcohol dependent individuals. Addiction 104:1006-1015

Leblond J, Ladouceur R, Blaszczynski A (2003) Which pathological gamblers will complete treatment? Br J Clin Psychol 42:205-209

Leiserson V, Pihl RO (2007) Reward-sensitivity, inhibition of rewardseeking, and dorsolateral prefrontal working memory function in problem gamblers not in treatment. J Gambl Stud 23:435-455

Leland DS, Paulus MP (2005) Increased risk-taking decision-making but not altered response to punishment in stimulant-using young adults. Drug Alcohol Depend 78:83-90

Lesieur HR, Blume SB (1987) The South Oaks Gambling Screen (SOGS): a new instrument for the identification of pathological gamblers. Am J Psychiatry 144:1184-1188

Li CS, Milivojevic V, Kemp K, Hong K, Sinha R (2006) Performance monitoring and stop signal inhibition in abstinent patients with cocaine dependence. Drug Alcohol Depend 85:205-212

Li CS, Huang C, Yan P, Paliwal P, Constable RT, Sinha R (2008) Neural correlates of post-error slowing during a stop signal task: a functional magnetic resonance imaging study. J Cogn Neurosci 20:1021-1029

Li CS, Luo X, Yan P, Bergquist K, Sinha R (2009) Altered impulse control in alcohol dependence: neural measures of stop signal performance. Alcohol Clin Exp Res 33:740-750

Lijffijt M, Kenemans JL, Verbaten MN, van Engeland H (2005) A meta-analytic review of stopping performance in attentiondeficit/hyperactivity disorder: deficient inhibitory motor control? J Abnorm Psychol 114:216-222

Logan GD (1994) On the ability to inhibit thought and action: a users' guide to the stop signal paradigm. In: Dagenbach $\mathrm{D}$, Carr TH (eds) Inhibitory processes in attention, memory and language. Academic Press, New York

Lyvers M (2000) "Loss of control" in alcoholism and drug addiction: a neuroscientific interpretation. Exp Clin Psychopharmacol 8:225-249

McElroy SL, Phillips KA, Keck PE Jr (1994) Obsessive compulsive spectrum disorder. J Clin Psychiatry 55(Suppl):33-51

Mitchell JM, Fields HL, D'Esposito M, Boettiger CA (2005) Impulsive responding in alcoholics. Alcohol Clin Exp Res 29:2158-2169

Monterosso JR, Aron AR, Cordova X, Xu J, London ED (2005) Deficits in response inhibition associated with chronic methamphetamine abuse. Drug Alcohol Depend 79:273-277

Nigg JT (2001) Is ADHD a disinhibitory disorder? Psychol Bull 127:571-598

Patton JH, Stanford MS, Barratt ES (1995) Factor structure of the Barratt impulsiveness scale. J Clin Psychol 51:768-774

Petry NM, Stinson FS, Grant BF (2005) Comorbidity of DSM-IV pathological gambling and other psychiatric disorders: results from the National Epidemiologic Survey on Alcohol and Related Conditions. J Clin Psychiatry 66:564-574

Pfefferbaum A, Desmond JE, Galloway C, Menon V, Glover GH, Sullivan EV (2001) Reorganization of frontal systems used by alcoholics for spatial working memory: an fMRI study. Neuroimage 14:7-20

Potenza MN (2006) Should addictive disorders include nonsubstance-related conditions? Addiction 101(Suppl 1):142-151

Quednow BB, Kuhn KU, Hoppe C, Westheide J, Maier W, Daum I, Wagner M (2007) Elevated impulsivity and impaired decisionmaking cognition in heavy users of MDMA ("Ecstasy"). Psychopharmacology (Berl) 189:517-530

Rabbitt PM (1966) Errors and error correction in choice-response tasks. J Exp Psychol 71:264-272 
Ridderinkhof KR, de Vlugt Y, Bramlage A, Spaan M, Elton M, Snel J, Band GP (2002) Alcohol consumption impairs detection of performance errors in mediofrontal cortex. Science 298:22092211

Rodriguez-Jimenez R, Avila C, Jimenez-Arriero MA, Ponce G, Monasor R, Jimenez M, Aragues M, Hoenicka J, Rubio G, Palomo T (2006) Impulsivity and sustained attention in pathological gamblers: influence of childhood ADHD history. J Gambl Stud 22:451-461

Rose AK, Duka T (2008) Effects of alcohol on inhibitory processes. Behav Pharmacol 19:284-291

Salo R, Nordahl TE, Possin K, Leamon M, Gibson DR, Galloway GP, Flynn NM, Henik A, Pfefferbaum A, Sullivan EV (2002) Preliminary evidence of reduced cognitive inhibition in methamphetamine-dependent individuals. Psychiatry Res 111:65-74

Schecklmann M, Ehlis AC, Plichta MM, Boutter HK, Metzger FG, Fallgatter AJ (2007) Altered frontal brain oxygenation in detoxified alcohol dependent patients with unaffected verbal fluency performance. Psychiatry Res 156:129-138
Slutske WS, Eisen S, True WR, Lyons MJ, Goldberg J, Tsuang M (2000) Common genetic vulnerability for pathological gambling and alcohol dependence in men. Arch Gen Psychiatry 57:666-673

Specker SM, Carlson GA, Christenson GA, Marcotte M (1995) Impulse control disorders and attention deficit disorder in pathological gamblers. Ann Clin Psychiatry 7:175-179

Stockwell T, Hodgson R, Edwards G, Taylor C, Rankin H (1979) The development of a questionnaire to measure severity of alcohol dependence. Br J Addict Alcohol Other Drugs 74:79-87

Verdejo-Garcia A, Lawrence AJ, Clark L (2008) Impulsivity as a vulnerability marker for substance-use disorders: review of findings from high-risk research, problem gamblers and genetic association studies. Neurosci Biobehav Rev 32:777-810

Weissenborn R, Duka T (2003) Acute alcohol effects on cognitive function in social drinkers: their relationship to drinking habits. Psychopharmacology (Berl) 165:306-312

Wojnar M, Ilgen MA, Czyz E, Strobbe S, Klimkiewicz A, Jakubczyk A, Glass J, Brower KJ (2009) Impulsive and non-impulsive suicide attempts in patients treated for alcohol dependence. $\mathrm{J}$ Affect Disord 115:131-139 